\section{Transport policy revisited}

SIR - It is surprising that your leading article about the Royal Commission's report on transport and the environment, "The motor-car as black sheep" (Nature 372, 115-116; 1994), concerns itself with the politics of transport to the virtual exclusion of scientific and technological issues, including sustainability. It is even more surprising that you show little awareness of what the report actually says.

You accuse the Royal Commission both of ignoring the attachment of British voters to the car and of succumbing to a "populist animus" against it. In fact the report recognizes, and documents, the advantages of car use, and the extent to which this is a necessity for many people, especially in rural areas. It also sets out clearly and objectively the serious consequences for the environment, and for the quality of life in Britain, if recent overall trends continue unchecked for the next 25 years and beyond.

It should be emphasized that the target proposed for carbon dioxide emissions from transport is to reduce them at the same rate as emissions from other sectors. We show in appendix D how that target can be achieved by measures that are not at all 'draconian'. For fuel duty we recommend an increase of 9 per cent a year in real terms; the government is already committed to an annual increase of at least 5 per cent. A major reason for our recommendation was to give strong encouragement to economy in the use of fuel. For cars that achieve our proposed target for increased fuel-efficiency, fuel costs would be broadly the same as at present.

You ignore the scope for increased fuel-efficiency in conventional vehicles. You also believe there will be major increases in fuel prices in any case as a result of market forces, although we found no evidence that this is likely over the next 25 years. We considered direct regulation (as in the United States or current German proposals), as a possible alternative means of ensuring that improvements in fuel-efficiency actually take place, but concluded that an economic instrument, in the form of increased fuel duty, is much to be preferred.

Although your article concentrates on the issue of greenhouse gases, this is only one of the eight objectives the Royal Commission proposed for a sustainable transport policy. The recommendations about the national trunk road programme follow from some of the other objectives, not (as you claim) from the targets for carbon dioxide emissions.

In particular, the Royal Commission places great importance on the environmental costs imposed by new infrastructure, such as loss or disruption of habitats, visual intrusion and severance of communities. We did not find it possible however, to estimate a money value for these costs. The estimates of environmental costs that you quote from the report therefore relate only to quantified costs, and we make it clear (7.17) that total environmental costs would be considerably higher.

Even if all external costs could be quantified, chapter 7 of the report explains why attempting to match costs and benefits at the margin is much more problematic than you imagine.

You recognize the dilemmas that must be resolved in order to find a sustainable transport policy. Given that these dilemmas affect every member of society, our report showed in detail why a fundamentally different approach to transport policy is now required, which will achieve an appropriate balance between the car and other modes of transport.

\section{John Houghton}

(Chairman)

Royal Commission

on Environmental Pollution,

Church House,

Great Smith Street,

London SW1P 3BL, UK

\section{A creative science}

SIR — Your 125th birthday celebrations gave us the chance to look both back and forwards. As director of the institution where you were kind enough to hold your birthday party (and where you also held your centenary symposium) I hope you will not think me churlish if I draw attention to a remarkable omission from the span of topics celebrated.

The capacity audience at the Royal Institution heard authoritative persuasive accounts of our search for ultimate regularities in matter at the microscopic and macroscopic limits, and explanations of the extraordinarily diverse structures found on length scales in between. From particle physics to cosmology, via biology, we were treated to a breathtaking panorama of the present state of human understanding. Nevertheless, all the science on display was occupied with explaining what is - with those structures and processes that mould the world we see. Yet there is one science, wholly missing from your programme, that occupies itself not just with observing the world, but with changing it.

Chemical synthesis rearranges the atoms in the cosmos the Good Lord gave us, producing new architectures of matter that simply were not there before. And having done so, it gives us properties the Universe had never seen. Until 1988, it must be counted extremely doubtful whether the elements $\mathrm{Y}, \mathrm{Ba}, \mathrm{Cu}$ and $\mathrm{O}$ had ever come into conjunction since the Big Bang, still less in the right atomic ratio to produce a substance with no electrical resistance at $90 \mathrm{~K}$. Those marvellous confections of $\mathrm{C}, \mathrm{H}, \mathrm{N}$ and $\mathrm{O}$ (with a smattering of other elements) that make up the biological world have also been creatively interfered with by chemists for more than a century, but with ever-growing vigour since you held your centenary party: we call them pharmaceuticals. Not only do they make us better, they make the economy better, too.

So let us celebrate the creative science that puts atoms together in new ways, synthetic chemistry.

\section{Peter Day}

Royal Institution

21 Albemarle Street,

London W1X 4BS, UK

\section{Black and blue}

SIR - During the past 20 years it has been the fashion at scientific meetings to present results with slides using white text on a blue background, which I will call blue slides. My assertion is that blue slides reduce readability and comprehension by at least about 20 per cent. It is best to use black text on a white background, or, if one absolutely must use colour, to use dark colours for the text on a faint coloured background such as faint blue or faint yellow.

Two examples illustrate the case. First, the renowned advertising expert, David Ogilvy, claimed that by changing an advertisement from white text on black background to black text on white, a charity organization doubled the income from an advertisement ${ }^{1}$

Second, IBM has found that we read computer screens, that is, white text on dark background, 20-30 per cent more slowly than the same text on paper, black text on white. This difference vanished when a high-resolution screen with black text on white background was compared with text on paper ${ }^{2}$. Apple has utilized this fact for a long time with the Macintosh, where normal use is black text on white background. Most Windows programs also use black text on white background.

There is only one group of scientists who might find it an advantage to use white text on black background, and that is X-ray physicians.

\section{Steinar Øvrebø}

National Institute of

Occupational Health

Pb 8149Dep.,

$\mathrm{N}-00330$ slo.

Norway

1. Ogiky on Advertising, (Pan, London, 1983).

2. Arbete och hälsa no 241987 Bildskjermarbete -en aktuell arbeitsmiljöfrảga (Stockholm, 1987). 